\section{ARTICLE}

\title{
Mental health of regular and reserve military veterans
}

\author{
Amy C. Iversen \& Neil Greenberg
}

\begin{abstract}
Amy C. Iversen studied medicine at the University of Cambridge and University College Hospital, London. After training in general medicine and neurology, she undertook her psychiatry training at the Maudsley Hospital in London. She is currently Clinical Lecturer in the Department of Psychological Medicine at the Institute of Psychiatry, London with a special interest in veterans' health. A focus of her research is health service utilisation, perceived needs and barriers to care in both still-serving and ex-service personnel. Neil Greenberg studied medicine at Southampton University and joined the Royal Navy as a student. Having completed his general duties medical officer time serving on ships, submarines and with the Royal Marines Commando, he trained in adult, liaison and forensic psychiatry. He is currently Senior Lecturer at King's College London and has a keen interest in organisational mental health, traumatic stress and in psychological health in military personnel.
\end{abstract}

Correspondence Dr Amy C. Iversen, 1 King's Centre for Military Health Research, Department of Psychological Medicine, Cutcombe Road, London SE5 9RJ, UK. Email: A.Iversen@iop.kcl.ac.uk

\section{SUMMARY}

The psychiatric problems of combat returnees are a topical and important issue given the ongoing conflicts in Iraq and Afghanistan. Despite the media prominence afforded to post-traumatic stress disorder, the most common disorders in the UK armed forces post-deployment are depression, alcohol misuse and anxiety disorders. Although the majority of service personnel do well after leaving military life, a minority who leave with psychiatric problems appear to be at risk of social exclusion and ongoing ill health. Reserve veterans are at greater risk as they do not have access to the usual support networks of the regular military. Steps to improve the knowledge and expertise of primary care services about veterans' mental health issues and increasing the availability of treatment options are important and are underway.
\end{abstract}

\section{DECLARATION OF INTEREST}

A.I. is a civilian researcher whose salary is paid by a grant from the Ministry of Defence (MOD). N.G. is a full-time active service medical officer who has been seconded to King's College Centre for Military Health Research as a liaison officer. The authors have not been directed in any way by the MOD in relation to this article.

Each year in the UK about 24000 men and women leave the British armed forces and enter civilian life (Defence Analytical Services Agency, 2007). There is increasing international recognition both within the military and within civilian society of "postconflict dysfunction', including (but not limited to) post-traumatic stress disorder (PTSD), in exservice personnel, particularly in recent years (Jones 2006).

The ongoing conflict in Iraq and Afghanistan has led to heightened interest in the welfare and health of regular and reserve combatants on their return from duty, and their return to civilian life. Media coverage has typically focused on the small minority who fare badly and drift into social exclusion such as those who become homeless and/or have severe mental health problems. Although much has been written about US war veterans, very little is known about their UK counterparts as, to date, there has been no long-term follow-up of UK military personnel after they leave the armed forces. The US literature must be interpreted with caution for the UK, first, because of theVietnam War experience, and second, because of the existence of the US Veterans Administration, which provides bespoke medical and psychiatric treatment solely for veterans. Therefore, where possible, we refer here to work that examines outcomes for UK veterans, as well as referencing key work from the USA. In this article, we focus on two groups of ex-combatants who may be particularly vulnerable in the event that they experience mental health problems: regular members of the armed forces who have left the military ('veterans') and volunteers in the reserve forces who have served in a combat situation ('reservists').

\section{Why is the mental health of veterans important?}

Literature from the USA on the Second World War has suggested that for most people military service had a positive effect on their life trajectory. Studies of men who served during the Second World War demonstrated that after leaving the armed forces, veteran status afforded these individuals greater educational opportunities, better qualifications, higher employment rates and bigger wage packets, partly because of the generous provision of the G.I. Bill of 1944 (US Department of Veterans Affairs 2008). In Germany, although those who fought in the Second World War initially had unfavourable occupational outcomes, these effects diminished rapidly over time as the German economy started to recover (Dandeker 2003). However, some of those who returned from the Vietnam War did not fare so well. The literature suggests that a proportion of veterans returning from theVietnam War to civilian life were disadvantaged in terms of earnings, jobs and educational attainment. This disadvantage was most acute for those with mental health problems (Anderson 1992). Veterans with PTSD often ended up with lower salaries, more enduring drug and alcohol problems, and a higher chance of ending up in prison (Dandeker 2003).

The US literature concerning those returning from the 1991 Gulf War has been no more encouraging, particularly for those who returned from combat unwell. Such individuals were more likely to be unemployed or to lose their job, to end up within the prison system and to be alcohol dependent. This is despite the fact that the land combat phase of the GulfWar lasted less than $100 \mathrm{~h}$ and was substantially 
less intense than more recent operations in Iraq and Afghanistan (Dandeker 2003).

In the military population (theatre-specific studies aside), those with mental health problems are more likely to leave service prematurely (Hoge 2002), experience lost work days (Engel 1999) and to end up socially excluded (e.g. homeless) (Rosenheck 1994). In the UK, despite the press focus on negative outcomes for war veterans, the limited existing evidence suggests that the majority do well after leaving the armed forces. A few years ago we were involved in a study that examined longitudinal outcomes for a cohort of service leavers from a large randomly selected military cohort; $87.5 \%$ of those who left were in full-time employment (Iversen 2005a). Deployment to the 1991 Gulf War did not disadvantage veterans in terms of employment; in fact, those who returned in good health from their Gulf service had a greater chance of being employed than those who had not been deployed there. This is not an uncommon phenomenon and has been called the 'medal effect' of a tour of duty. However, those who experienced mental health problems on their return were more likely to leave the military and to be unemployed after leaving. Veterans' symptoms appeared to remain fairly stable and persistent after leaving the armed forces. Taken together, these results suggest that there is a small but important minority of veterans who leave the services with mental health problems, remain chronically unwell and are vulnerable to social exclusion (e.g. marital breakdown, unemployment, homelessness).

\section{Common mental health problems in veterans}

Large-scale studies of veterans of the 1991 Gulf War have found that the most common mental health problems are depression, anxiety disorders and alcohol misuse/dependence (Ismail 2002; Ikin 2004; Toomey 2007). A small cross-sectional study in the UK of Gulf, Bosnia and 'Era' (personnel who served in the military at the same time but were not deployed on these operations) veterans who had all left the military revealed the same findings (Iversen 2005b). This is mirrored in both the stillserving US military population (Riddle 2007) and in the UK general population (Jenkins 1997). A similar range of disorders has been reported in large US samples of the military population. Hoge and colleagues (2002) examined the range of disorders accounting for hospital admissions and out-patient visits in the US military. Alcohol and substance misuse, adjustment disorders, mood disorders and personality disorders were the most common diagnoses, with PTSD accounting for only $2 \%$ of out-patient visits and $1 \%$ of admissions. Riddle and colleagues (2007) reported that the most common
BOX 1 The most common mental health problems in veterans, in approximate order of prevalence
- Adjustment disorders
- Alcohol misuse
- Depressive disorders
- Personality disorders
- Post-traumatic stress disorder
- Drug misuse

disorders in a representative sample of the US military were alcohol dependence and depression. The findings of these studies (Box 1) are at odds with the focus given to PTSD in the press. Reasons for this are explored below.

\section{Why is there such a focus on post-combat PTSD?}

The USA's experiences of service personnel returning unwell from theVietnam War have shaped the landscape of traumatology for the past 30 years, and indeed were responsible for the introduction of the term 'post-traumatic stress disorder' into the Diagnostic and Statistical Manual of Mental Disorders in 1980 (Marlowe 2000). Despite the fact that historians have described the Vietnam War as 'low intensity' for US armed forces (Jones 2001), the most influential congressionally mandated outcome study, the National Vietnam Veterans Readjustment Study (NVVRS), found a lifetime prevalence of $30.9 \%$ and a current prevalence of $15.2 \%$ for PTSD (Kulka 1990). This seems a curious finding given that other commentators report that about 85\% of Vietnam veterans returned to productive, reasonably well-adjusted lives after the war (Burkett 1998), and some informal sources suggest that 74\% of veterans, given the chance, would 'do it all again' (Vietnam Helicopter Flight Crew Network 2008). The NVVRS findings were also in contrast to the Centre for Disease Control's Vietnam Experience Study, which reported rates of $14.7 \%$ for lifetime PTSD and 2.2\% for current PTSD 12 years after the Vietnam War ended (Centre for Disease Control Vietnam Experience Study Group 1988). Claims that these results are not congruent with the numbers of combat troops inVietnam and claims and counterclaims about their occupational adjustment continue to excite controversy, as witnessed by a heated debate in the Journal of Traumatic Stress in August 2007. Recent re-examination of the NVVRS taking account of functional impairment associated with PTSD symptoms has re-calculated the rates as $18.7 \%$ for lifetime prevalence and $15.2 \% 12$ years after the war (Dohrenwend 2006). Moreover, the 
trajectory for most veterans, even those with the most severe symptoms, was towards improvement in symptoms or remission.

Despite these findings, US military veterans' claims for PTSD have increased from 120265 in 1999 to 215871 in 2004, with total payments rising from US $\$ 1.72$ billion to US $\$ 4.28$ billion in the same period. Many of the claimants areVietnam veterans claiming for 'delayed' PTSD. This situation has led the Committee on Veterans Compensation for Posttraumatic Stress Disorder (2007) to describe PTSD in veterans as a 'significant public health problem'. Among veterans seeking mental health treatment in Veterans Administration clinics, most (up to 94\%) concurrently apply for PTSD disability benefits.

It is clear that further research is needed to refine our understanding of the individual factors that contribute to symptom chronicity and ongoing functional impairment in order that we may identify, and target services towards, the most vulnerable of combat returnees who have PTSD symptoms.

\section{What will the burden of mental disorders be like from the Iraq War?}

Many people in the USA, including the former President George W. Bush, have made reference to the similarities between the current conflict in Iraq and that in Vietnam (both are wars without fronts where it is difficult for soldiers to distinguish friend from foe among the civilian population).

'The New Vietnam' has commentators predicting a deluge of troubled soldiers from the current conflict. Studies from the USA to date have indeed revealed that there appears to be a substantial burden of mental health problems associated with the recent conflicts in Iraq and Afghanistan. Hoge and colleagues (2004) conducted an anonymous survey of combatants before deployment and again 3-4 months after returning from deployment to Iraq or Afghanistan. Those who had completed a tour of duty in Iraq had significantly higher rates of major depression, generalised anxiety disorder and PTSD than those who had been deployed to Afghanistan. Furthermore, rates were higher than those seen before deployment to Iraq. Background rates of PTSD in the US military appear to be higher than in the UK armed forces. The authors also report that $9.3 \%$ of the US military fulfilled the diagnostic criteria for PTSD prior to deployment to Iraq and this rose to $17.1 \%$ on return (compared with $7 \%$ in UK combat troops using an identical measure).

Larger-scale studies have confirmed that there are differences in the rate of mental illness in US troops compared with UK troops. For example, a study based on routine post-appointment health assessment of US service personnel returning from deployment screened survey responses from 16000 returnees from Afghanistan and 222000 returnees from Iraq (Hoge 2006). The prevalence of mental health problems was $19.1 \%$ among those returning from Iraq, compared with $11.3 \%$ in those returning from Afghanistan and 8.5\% in returnees from other locations. Mental health problems reported on the post-deployment assessment were significantly associated with combat experiences, mental healthcare referral and utilisation, and attrition from military service. The reasons for the difference between the US and UK rates of PTSD post-combat are a matter of ongoing discussion, but it is likely that they relate to differences in combat exposure, length of tour (the US military have deployed their soldiers in the field for almost twice as long as their European allies since the First World War) and in the age of the combatants deployed by the respective countries.

Between January and June 2003, 66000 British service personnel were deployed in the Persian Gulf. Between 18 January and 28 April 2003, 48000 took part in the first stage of hostilities in Iraq (hereafter referred to as Operation Telic 1). Since that time, British service personnel have continued to be deployed in Iraq in increasingly arduous operations. Although the 'war-fighting' period has officially ended, it is well recognised that deployments have become increasingly difficult and dangerous because of insurgency and sectarian violence. At the time of writing, coalition forces' casualties to date were numbered at 4544 people, 178 of whom are British. At present, the majority of those who have served in Iraq are still-serving personnel, and therefore the burden of mental health problems for veterans of the Iraq conflict remains unclear. Combat Stress, a leading service charity in the UK, reported a fourfold increase in referrals of ex-service personnel between 2005 and 2007, 283 of whom served in Iraq or Afghanistan, although without a denominator such data are always difficult to interpret (Combat Stress, personal communication 2007).

\section{Risk of psychiatric injury for reservists}

There are approximately 36000 volunteer reservists in the UK at present. The largest of the UK's reserve services is the army, a quarter of the total strength of which is contributed by the Territorial Army. The Iraq War necessitated the first compulsory call-up of reservists from all three armed services since the Korean War in the 1950s, with 12580 mobilised.

\section{Past conflicts}

Previous studies confirm that there is an excess risk of psychiatric injury for reservists. McAllister and colleagues (2004) investigated the rate of 
psychiatric casualties within a UK regular army division deployed to Iraq during the 2003 conflict, and reported a higher rate of possible psychiatric injury in less experienced personnel and reservists who were deployed with them. The US reserve personnel who served in the 1991 and 2003 Iraq Wars were found to be at greater risk of mental ill health than their regular counterparts (Iowa Persian Gulf Study Group 1997). Reservists also reported greater physical trauma and were more likely to be currently suffering from chronic fatigue, alcohol misuse and other self-reported ill health (Iowa Persian Gulf Study Group 1997).

\section{UK reservists deployed to Iraq}

The issues of health and well-being of UK armed forces is topical and has been addressed by the establishment of a large epidemiological cohort of UK service personnel who were deployed on Operation Telic 1 (the main war-fighting period), with a comparison cohort of those who were either deployed elsewhere or were in the military at the time of Operation Telic 1 but were not deployed. Stage 1 of the study, a cross-sectional postal questionnairebased study, was completed in March 2006 and the main results have been published (Hotopf 2006). The participation rate was $62.3 \%(n=4722)$ in the deployed sample and $56.3 \%(n=5550)$ in the comparison sample. In the deployed sample, only the presence of multiple physical symptoms was marginally associated with deployment $(\mathrm{OR}=1.32$, 95\% CI 1.14-1.53), but for reservists deployment was associated with an increase in the prevalence of common mental disorders $(\mathrm{OR}=2.47,95 \%$ CI 1.35$4.52)$ and fatigue (OR $=1.78,95 \%$ CI 1.09-2.91). The authors concluded that there is evidence of a clinically and statistically significant adverse effect on health in reservists. In a more detailed analysis, Browne et al (2007) found significant unadjusted odds ratios for five negative health outcomes: common mental disorders, PTSD, fatigue, multiple symptoms, and fair or poor health on the Short Form-36 questionnaire. Compared with regular service personnel, reservists reported higher levels of self-perceived risk to life and trauma in theatre, and lower unit cohesion. They also reported more problems at home during deployment, more negative homecoming experiences and poorer marital satisfaction. Of note is that adjustment for military factors (e.g. role in theatre, exposures, cohesion) accounted for the excess of all adverse health outcomes except for PTSD. The PTSD health effect disappeared only when adjustment was made for problems at home. One explanation for the increase in adverse health outcomes is that, for reservists at least, adverse domestic experiences may be exacerbating and prolonging PTSD symptoms (Browne 2007). Qualitative work confirms that marital problems are a common concern among reservists, many of whom felt that their families did not have access to adequate welfare services during their deployment (Eversden-French 2007). Also of interest is the finding that reservists felt that deployment put their lives at greater risk than did regulars. This may reflect reservists' prior lack of exposure to military environments. The majority of reservists will have served in support arms and, although everyone is at risk of physical injury, their risk of being harmed would have been substantially lower than the risks faced by combat troops, who had relatively few reservists among them.

Deployed reservists are likely to have different expectations of military obligations, different levels of preparedness and fitness, and are likely to have been deployed as individual reinforcements to theatre without other members of their home unit (thereby missing out on peer support). Unlike regular soldiers, at the end of the early Operation Telic 1 deployments, reservists were dispersed immediately on return to the UK and thus their military social networks, which can be very supportive when it comes to post-deployment adjustment, may have been lost. This military social network is replaced by civilian relationships, including those with employers, that may offer less understanding of and support for reservists' concerns. Reservists in subsequent Iraq deployments have faced an additional problem of a relative decline in overall support from the wider civilian society for military operations in Iraq as time goes on. This factor may contribute to an increase in the risk of psychiatric injury, as it is purported to have done after the Vietnam War (Marlowe 2000).

\section{Risk factors for mental health disorders in veterans}

Riddle and colleagues (2007) examined the baseline prevalence of mental disorders in the US military in a cohort of 77047 participants and found that certain military subpopulations, including female, younger, less educated, single, White, short-term service enlisted personnel, and army personnel, were more likely to have poor mental health. In the UK veteran population, a similar, although smaller $(n=496)$, study found that those who served in the army, were single, and were from lower ranks were most at risk of reporting mental health problems (Iversen 2005b). Studies from both the UK and the USA have shown that combatants who had preenlistment/childhood adversity were more likely to experience mental health problems on return from deployment (Cabrera 2007; Iversen 2007). 


\section{Improving the mental health of ex-service personnel and reservists}

In 2001, King's College London performed a scoping study to look at the mental health needs of veterans and how they were currently being met (Dandeker 2003). A clear view that emerged from the stakeholders and veterans interviewed was that the mental health needs of veterans were not being met by existing National Health Service (NHS) provisions at that time. A more recent cross-sectional study examining health service utilisation in those who have left the British armed forces (Iversen 2005b) has confirmed the anecdotal impression. It found that only $58 \%$ of those who reported mental health problems were currently seeking help from any professional, and only $28 \%$ had sought help from a non-governmental organisation. Of those who had sought help, the majority were being cared for within primary care and only $28 \%$ had been seen in secondary care. Just 7\% had received support from a community psychiatric nurse and only $4 \%$ had been offered cognitive-behavioural therapy, despite its recommendation by the National Institute for Health and Clinical Excellence as an effective treatment for depression and PTSD (National Collaborating Centre for Mental Health 2005). Similarly, only $23-40 \%$ of US ex-combatants who had returned from operational duties with mental health problems had sought mental healthcare (Hoge 2006). Those with mental health problems were much more likely to report barriers to care and concerns about stigmatisation than those who were well (Hoge 2004). In a study in the Royal Navy, distressed service personnel reported selfstigmatising beliefs two to three times more often than those who were not distressed (Langston 2009). Individuals with stress were also more

BOX 2 Sources of help for UK veterans with mental health problems

\section{General advice for veterans}

Service Personnel and Veterans Agency (www.veterans-uk.info). Includes information about the Medical Assessment Programme at St Thomas' Hospital, London (www.veterans-uk.info/map/ announcement.html). Free veterans' helpline: 08001692277

Combat Stress (www.combatstress.org.uk). Tel: 01372841600

Soldiers, Sailors, Airmen and Families Association (SSAFA) Forces Help (www.ssafa.org.uk). Tel: 08007314880

\section{Veterans who are homeless}

Veterans Aid (www.veterans-aid.net). Tel: 02078282468

Special services for reservists with mental health problems

Reserves Mental Health Programme (www.mod.uk/NR/rdonlyres/45EAE310-13EC-403F-BF2F51AE56520CE3/0/rmhp.pdf). Tel: 08000326258 sensitive to barriers of care and were less likely to believe that any help they might receive would be rendered confidentially (Langston 2009). This may explain the finding by the charity Combat Stress that the average delay between symptom onset and presentation to services is 13 years for veterans (Combat Stress, personal communication 2007). One attempt to address stigma while people are still serving has been the introduction of a peer-led stress management system which is embedded in the chain of command and does not rely on individuals seeking help from mental health professionals (Gould 2007). It is hoped that over time such programmes might result in a cultural shift within the organisation, destigmatising help-seeking and treatment of mental health problems in the still-serving military, which will in turn make help-seeking more likely once people leave military service.

\section{Improving access to care}

So what can be done in the meantime? One important and practical step is to improve veterans' and civilian service providers' knowledge of veterans' issues and the services that are already available. As of August 2007, any veterans with operational experience since the Falklands War have been able to access free, expert, confidential mental health assessment by a psychiatrist with extensive military experience and knowledge of military psychiatry (Ministry of Defence 2007a). There is a variety of other services available for veterans' wider health issues (Box 2), including Combat Stress, a specialist charity providing mental health assessment and treatment solely for military veterans. It is also important for clinicians to be alert to mental health problems in ex-service personnel, as such problems often present in a complex way and are compounded by multiple social problems such as difficulties with employment, marital breakdown and debt. Consequently, many veterans do not fit conveniently into existing diagnostic/treatment algorithms. In addition, as there appears to be a high level of reticence among veterans to consult their doctor and discuss mental health problems, civilian service providers may need to facilitate disclosure by discrete inquiry into key areas (Box 3).

Clearly, encouraging veterans to consult their primary care providers will form the main route into assessment and treatment, especially if a community-based stepped care model of mental health service provision for veterans is implemented as is envisaged currently. In the UK, a pilot project is underway using 'community veterans mental health therapists' to facilitate the links between individual veterans in the community and providers such as primary care trusts, community mental health 
BOX 3 Helping post-combat veterans and reservists to disclose psychological difficulties

Ask about:

- Sleep/nightmares

- Family/marital relationships

- Mood

- Anger

- Persistent intrusive recollection/rumination about combat experiences

- Alcohol use

services and social services. Many veterans have expressed the desire to work with therapists and doctors who have expertise or experience of service in the military and thus it is envisaged that community veteran therapists will themselves have an exmilitary background (Ministry of Defence 2007b). By working with a community veteran therapist, it is hoped that veterans will have facilitated access to a local network of providers with multidisciplinary expertise and experience of working with trauma and its sequelae.

\section{Accessing services for reservists}

Until very recently, post-deployment healthcare for reservists in the UK was not covered by the Defence Medical Services (the military health service) and was instead the sole responsibility of the NHS. For many reservists this represented a barrier to care, as many report anecdotally that local NHS healthcare providers are ignorant of or insensitive to psychiatric problems related to military service. This may be because the era in which most general practitioners and/or hospital consultants had themselves seen service in the Second World War or national service has now passed. However, in response to the emerging evidence, the UK's Ministry of Defence has provided a bespoke militarybased assessment service available for reservists with mental health symptoms or illness thought to be related to deployment. Those found to have deployment-related psychiatric disorder are offered treatment at their local military Department of Community Mental Health. However, it is not clear whether such services are being utilised effectively by reservists who are unwell at present, as the takeup rates for the Reserves Mental Health Programme remains low. Again, improving recognition of problems in primary care and improving general practitioners' knowledge of appropriate sources of help for reservists are pivotal in ensuring their needs are met.

\section{Future work}

Finally, to address the gaps in our understanding of the well-being of reservists and the ex-service community, large-scale, long-term longitudinal studies of outcomes for service personnel after they return from combat or when they leave the armed forces will be crucial. The major advantage of examining outcomes for veterans and reservists via a cohort study of this type is that it will allow policy makers and scientists alike to unpick the relative contribution of pre-service, in-service and postservice vulnerabilities to veterans' and reservists' current difficulties.

\section{References}

Anderson K, Mitchell J (1992) Effects of military experience on mental health problems and work behaviour. Medical Care; 30: 554-63.

Browne T, Hull L, Horn 0, et al (2007) Explanations for the increase in mental health problems in UK reserve forces who have served in Iraq. British Journal of Psychiatry; 190: 484-9.

Burkett B, Whitley G (1998) Stolen Valour: How the Vietnam Generation was Robbed of its Heroes and its History. Verity Press.

Cabrera OA, Hoge CW, Bliese P, et al (2007) Childhood adversity and combat: effects on depression and post traumatic stress. American Journal of Preventive Medicine; 33: 77-82.

Centre for Disease Control Vietnam Experience Study Group (1988) Health status of Vietnam veterans. I. Psychosocial characteristics. Centre for Disease Control Vietnam Experience Study. JAMA; 259: 2701-7.

Committee on Veterans Compensation for Posttraumatic Stress Disorder, Institute of Medicine, National Research Council (2007) PTSD Compensation and Military Service. National Academic Press.

Dandeker C, Wessely S , Iversen A, et al (2003) Improving the Delivery of Cross Departmental Support and Services for Veterans. Ministry of Defence (http://www. veterans-uk.com/pdfs/publications/misc/kings_college_report_jul_03.pdf).

Defence Analytical Services Agency (2007) DASA Outflow Statistics. Table 4.DASA /http://www.dasa.mod.uk/applications/newWeb/www/apps/publications/pub ViewFile . php ? content $=34 \&$ date $=2008-12-19 \&$ type $=$ html\& $\&$ ublishTime $=$ 09:30:00|.

Dohrenwend BP, Turner JB, Turse NA, et al (2006) The psychological risks of Vietnam for U.S. veterans: a revisit with new data and methods. Science; 313: 979-82.

Engel CC Jr, Ursano R, Magruder C, et al (1999) Psychological conditions diagnosed among veterans seeking Department of Defense Care for Gulf Warrelated health concerns. Journal of Occupational and Environmental Medicine; 41: 384-92.

Eversden-French C, Dandeker C, Hatch S, et al (2007) The significance of family welfare in the well-being of Volunteer Reservists deployed to Iraq: a mixed methods study of UK Territorial Army personnel. 2007 Biennial International Conference on Armed Forces and Society: Conference Abstracts. Inter-University Seminar on Armed Forces and Society, Loyola University, Chicago.

Gould M, Greenberg N, Hetherton J (2007) Stigma and the military: evaluation of a PTSD psychoeducational program. Journal of Traumatic Stress; 20 : 505-15.

Hoge CW, Lesikar SE, Guevara R, et al (2002) Mental disorders among U.S. military personnel in the 1990s: association with high levels of health care utilization and early military attrition. American Journal of Psychiatry; 159: 1576-83.

Hoge CW, Castro CA, Messer SC, et al (2004) Combat duty in Iraq and Afghanistan, mental health problems, and barriers to care. New England Journal of Medicine; 351: 13-22.

Hoge CW, Auchterlonie JL, Milliken CS (2006) Mental health problems, use of mental health services, and attrition from military service after returning from deployment to Iraq or Afghanistan. JAMA; 295: 1023-32. 


\begin{tabular}{|c|c|c|c|c|}
\hline \multicolumn{5}{|c|}{ MCO answers } \\
\hline 1 & 2 & 3 & 4 & 5 \\
\hline af & af & at & af & af \\
\hline $\mathrm{bt}$ & $b f$ & $b f$ & $b f$ & $b f$ \\
\hline$c f$ & $c f$ & $c f$ & $c t$ & $c t$ \\
\hline$d f$ & $d f$ & $d f$ & $d f$ & $d f$ \\
\hline ef & et & ef & ef & ef \\
\hline
\end{tabular}

Hotopf M, Hull L, Fear NT, et al (2006) The health of UK military personnel who deployed to the 2003 Iraq war: a cohort study. Lancet; 367: 1731-41.

Ikin JF, Sim MR, Creamer MC, et al (2004) War-related psychological stressors and risk of psychological disorders in Australian veterans of the 1991 Gulf War. British Journal of Psychiatry; 185: 116-26.

lowa Persian Gulf Study Group (1997) Self-reported illness and health status among Persian Gulf War veterans. A population-based study. JAMA; 277: $238-45$

Ismail K, Kent K, Brugha T, et al (2002) The mental health of UK Gulf war veterans: phase 2 of a two phase cohort study. BMJ; 325: 576

Iversen A, Nikolaou V, Greenberg N, et al (2005a) What happens to British veterans when they leave the armed forces? European Journal of Public Health; 15: $175-84$.

Iversen A, Dyson C, Smith N, et al (2005b) 'Goodbye and good luck': the mental health needs and treatment experiences of British ex-service personnel. British Journal of Psychiatry; 186: 480-6.

Iversen AC, Fear NT, Simonoff E, et al (2007) Influence of childhood adversity on health among male UK military personnel. British Journal of Psychiatry; 191: 506-11.

Jenkins R, Lewis G, Bebbington P, et al (1997) The National Psychiatric Morbidity surveys of Great Britain - initial findings from the household survey. Psychological Medicine; 27: 775-89.

Jones E, Wessely S (2001) Psychiatric battle casualties: an intra- and interwar comparison. British Journal of Psychiatry; 178: 242-7.

Jones E, Wessely S (2006) Shell Shock to PTSD. Military Psychiatry from 1900 to the Gulf War (Maudsley Monographs). Psychology Press.

Kulka R, Schlenger W, Fairbank J, et al (1990) Trauma and the Vietnam War Generation: Report of Findings From the National Vietnam Veterans Readjustment Study. Routledge.
Langston V, Greenberg N, Fear N, et al (2009) Stigma and mental health in the Royal Navy. Journal of Mental Health; in press.

Marlowe DH (2000) Psychological and Psychosocial Consequences of Combat and Deployment. With Special Emphasis on the Gulf War. Rand Corporation.

McAllister P, Blaire S, Philpott S (2004) Op Telic - a field mental health team in the general support medical setting. Journal of the Royal Army Medical Corps; 50: $107-12$

Ministry of Defence (2007a) Veterans Health - Extension of the Scope of the Medical Assessment Programme (MAP). Ministry of Defence (http://www. veterans-uk.info/map/announcement.htmll.

Ministry of Defence (2007b) Veterans Issues: Community Veterans Mental Health Pilot. Ministry of Defence (http://www.veterans-uk.com/mental_health/ faq.htmll.

National Collaborating Centre for Mental Health (2005) Post-traumatic Stress Disorder (PTSD): The Management of PTSD in Adults and Children in Primary and Secondary Care. Clinical Guideline 26. National Institute for Health and Clinical Excellence.

Riddle JR, Smith TC, Smith B, et al (2007) Millennium Cohort: the 2001-2003 baseline prevalence of mental disorders in the U.S. military. Journal of Clinical Epidemiology; 60: 192-201.

Rosenheck R, Frisman L, Chung AM (1994) The proportion of veterans among homeless men. American Journal of Public Health; 84: 466-9.

US Department of Veterans Affairs (2008) GI Bill history (http://www.gibill. va.gov/GI_Bill_Info/history.htm)

Toomey R, Kang HK, Karlinsky J, et al (2007) Mental health of US Gulf War veterans 10 years after the war. British Journal of Psychiatry; 190: 385-93.

Vietnam Helicopter Flight Crew Network (2008) Statistics about the Vietnam War (http://www.vhfcn.org/stat.htmll.

\section{MCOs}

1 The most common mental health problem in veterans is:

a panic disorder

b depressive disorder

c personality disorder

d post-traumatic stress disorder

e drug dependence.

2 Which of the following statements is not true about reservists:

a the majority of reservists serve in support roles while deployed

b reservists are more likely than regular soldiers to have mental health problems after returning from combat

c reservists perceive that they are more at risk of injury and harm during deployment

$d$ reservists perceive that they have more trouble at home during deployment e reservists represent about an eighth of the strength of the British army.

3 Among military personnel, mental health problems are more common in:

a women

b officer ranks

c those who are married

d those from an ethnic minority group

e those who are older.

4 As regards the services available to veterans and reservists in the UK:

a there is no special service to assess the mental health of reservists in the UK

b veterans with mental health problems are not entitled to a specialist assessment by Ministry of Defence clinicians

c stigma is major barrier to help-seeking in veterans

d cognitive-behavioural therapy is unlikely to help with post-traumatic stress disorder

e most veterans have complex needs that cannot be met by the NHS.

\section{As regards combat veterans:}

a those with mental health problems are more likely to stay in the military

b rates of unemployment in those who leave are about $25 \%$

c data from the Second World War suggest that many veterans benefited in terms of jobs and education as a result of their military service

d those who served in the 1991 Gulf War were more likely to be unemployed than those who were in the military but did not deploy

e evidence suggests that veterans' symptoms get worse after they leave the military. 